\title{
CTLA4-Ig (abatacept) therapy modulates T cell effector functions in autoantibody-positive rheumatoid arthritis patients
}

Jennifer Pieper', Jessica Herrath', Sukanya Raghavan', Khalid Muhammad', Ronald van Vollenhoven² and Vivianne Malmström ${ }^{1 *}$

\begin{abstract}
Background: Rheumatoid arthritis is a chronic inflammatory disease with a strong MHC class II component and where many patients develop characteristic autoantibodies towards the noncoding amino acid citrulline. Such anti-citrullinated protein antibodies (ACPA) have recently been put forward as an independent predictive factor for treatment response by co-stimulation blockade by CTLA4-Ig (abatacept). We have performed a mechanism of action study to dissect $T$ cell functionality in RA patients with long-standing disease undergoing abatacept treatment and the influence of ACPA status.

Results: Peripheral blood samples were collected from RA patients as they started CTLA4-lg treatment and 3 and 6 months later. A general decrease of regulatory $T$ cell subsets was observed in the cohort. Additionally within the ACPA-positive group significant down-regulation of all key T cell effector subsets including Th1, Th2, and Th17 was observed by analyzing cytokines by intracellular flow cytometry and in cell culture supernatants.

RA synovial fluid samples were cultured in vitro in the presence or absence of CTLA4-Ig (abatacept). T cell cytokine production was diminished, but without increasing the functional capacity of CD4+CD25hi regulatory $T$ cells as previously demonstrated in the context of TNF-blockade and anti-IL6R therapy.

Conclusions: Our immunological study of T cell functionality in RA patients, both ACPA-positive and ACPA-negative, starting biological therapy with the co-stimulation blockade abatacept (CTLA4-lg) supports the recently published registry study implicating ACPA seropositivity as an independent predictive factor to treatment response as we observed the most striking effect on T cell subset modulation in ACPA-positive patients. These data further support the notion of RA as a disease with several sub-entities, where the ACPA-positive fraction represents a classical HLA-associated autoimmune disorder while ACPA-negative patients may have other driving forces apart from classical adaptive immune responses.
\end{abstract}

Keywords: Rheumatoid arthritis, Autoimmunity, T lymphocyte, Cytokines, Regulatory T cells, Abatacept, ACPA

\section{Background}

Rheumatoid arthritis (RA) is a systemic inflammatory disorder characterized by chronic joint inflammation and continuous cell infiltration into the synovium. The presence of anti-citrullinated protein antibodies (ACPA) in a large subset of patients supports the notion of an autoimmune etiology and is tightly associated with the

\footnotetext{
* Correspondence: vivianne.malmstrom@ki.se

${ }^{1}$ Rheumatology Unit, Department of Medicine at Karolinska University

Hospital, Karolinska Institute, Solna, Stockholm, Sweden

Full list of author information is available at the end of the article
}

HLA-DR shared epitope alleles, which suggests that CD4+ T cells are important [1]. Indeed, CD4+ T cells are abundant in both synovial tissue and in synovial fluid. Furthermore, ACPA-positive RA patients develop generally a more aggressive disease than ACPA-negative patients $[2,3]$.

The role of CD4+ T cells in RA pathophysiology may be mediated through Th1 effector functions, mainly IFN- $\gamma$ secretion [4], Th17 activity or induction of ACPA $[5,6]$, leading finally to bone and cartilage destruction. It has also been suggested that regulatory $\mathrm{T}$ cell (Treg)

\section{Biomed Central}


function may be impaired in RA [7]. Tregs represent a crucial $\mathrm{T}$ cell subset in the maintenance of immune homeostasis and are significantly enriched in the synovial fluid of RA patients [8,9].

Commonly used biological therapies for RA target mainly cytokine pathways, with the exception of the $B$ cell depleting agent rituximab and abatacept, a chimeric CTLA4 and IgG Fc fusion protein modulating T cell activation. Abatacept is believed to work by blocking CD28 costimulation and thereby interfering with $\mathrm{T}$ cell-APC interaction and limiting $\mathrm{T}$ cell activation. Use of abatacept is associated with reduction in joint inflammation, pain and joint damage in patients with active RA [10]. Recently it has been reported that abatacept shows a better clinical response in ACPA-positive as compared to ACPA-negative patients [11]. Many lines of evidence suggest that the CD4+ T cell compartment is more active in ACPA-positive as compared to ACPA-negative RA.

In this study we compared $\mathrm{T}$ cell functionality in the context of ACPA status in patients before and after $\mathrm{T}$ cell costimulation blockade by abatacept. Our data demonstrate that abatacept therapy significantly reduces circulating Treg frequencies, as well as effector cytokine output from Th1, Th2 and Th17 cells in ACPA-positive patients, but not in ACPA-negative patients. We further validated these findings in synovial fluid cell cultures where pharmacological doses of abatacept were added. We conclude that abatacept interferes with the full range of $\mathrm{T}$ cell subsets, especially T cells in ACPA-positive patients.

\section{Results}

Unchanged levels of autoantibodies in abatacept-treated patients

For this study 33 patients starting on abatacept therapy were included and peripheral blood was collected at baseline and after 3 and 6 months. It has recently been reported that treatment with abatacept shows better results in ACPA-positive individuals, and we therefore examined both the ACPA status of our patient cohort at baseline and investigated changes in ACPA levels from baseline to the 6 months follow-up.

In the cohort, 23 of 33 investigated patients had serum antibodies against citrullinated proteins (Figure 1), but we did not observe any significant changes in the ACPA levels during the study period, nor did the ACPA status predict clinical outcome; however this study was not intended and powered to adequately address this issue. Our aim instead was to investigate the adaptive immune function.

\section{Diminished T cell effector functions in patients treated with abatacept}

We started by investigating the most relevant cytokines in the context of RA, namely IFN- $\gamma$, TNF and IL-17, as

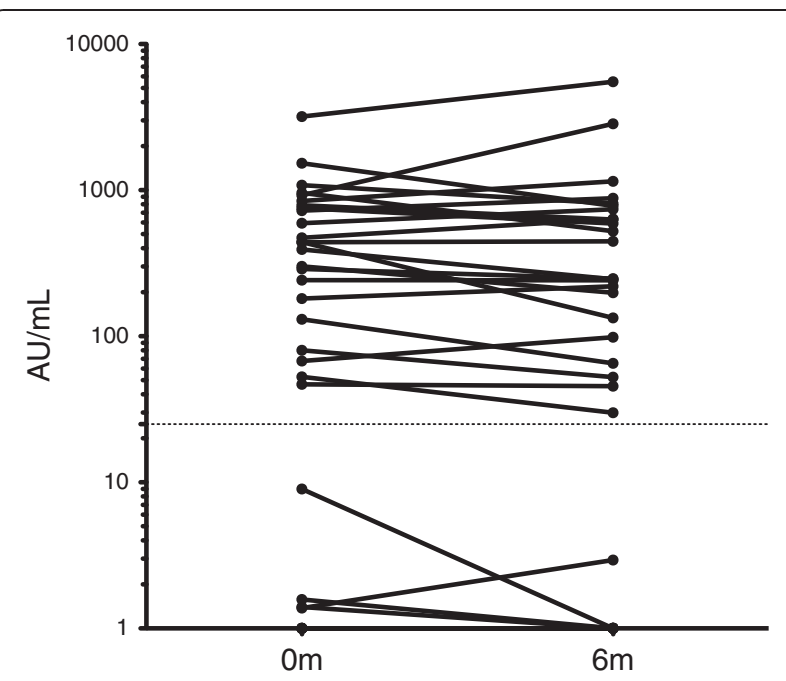

Figure 1 ACPA level at baseline and 6 months following abatacept treatment. ACPA level was measured in serum of 33 RA patients undergoing abatacept therapy at baseline and 6 months following treatment. Samples $\geq 25 \mathrm{AU} / \mathrm{mL}$ are defined as positive.

they are all implicated in disease pathogenesis and are central in Th1 and Th17 function.

At baseline and six months following abatacept therapy, PBMCs from 19 patients were utilized for polyclonal $\mathrm{T}$ cell stimulation for both 6 hrs and 5 days, and subsequently intracellular cytokine stainings were performed. By this approach, each individual is its own control. Representative flow cytometry stainings are depicted in Figure 2A. While unstimulated cells did not produce cytokines, robust production was observed following polyclonal stimulation (Figure 2A).

Our data show that $\mathrm{T}$ cells of the Th1 subset from ACPA-positive patients are clearly affected by abatacept, as both TNF and IFN- $\gamma$ production by CD4+ T cells were significantly decreased at the day 5 read-out (Figure 2D). Only minor secretion of IL-17A could be observed after polyclonal stimulation, but we still saw a tendency in diminished IL-17A production after treatment (Figure 2B and D). In contrast, cells from ACPA-negative patients displayed the opposite pattern with increased cytokine production of TNF, IFN- $\gamma$ and IL-17A (Figure 2C and E).

Our multiparameter flow approach allows a comparison of the different cytokines within each patient sample. To this end we calculated ratios of each cytokine and sample by comparing 6 months with baseline. Again, all ACPA-negative patients showed higher ratios $(>1)$, i.e. increased expression while the ACPA-positive patients mostly displayed reduced cytokine output $(<1)$ (data not shown). From these ratios we further determined the spearman's rank correlation coefficients for the different cytokine combinations. A significant correlation between all examined cytokines (IFN- $\gamma /$ TNF: $r=0.651, p=0.003$; 


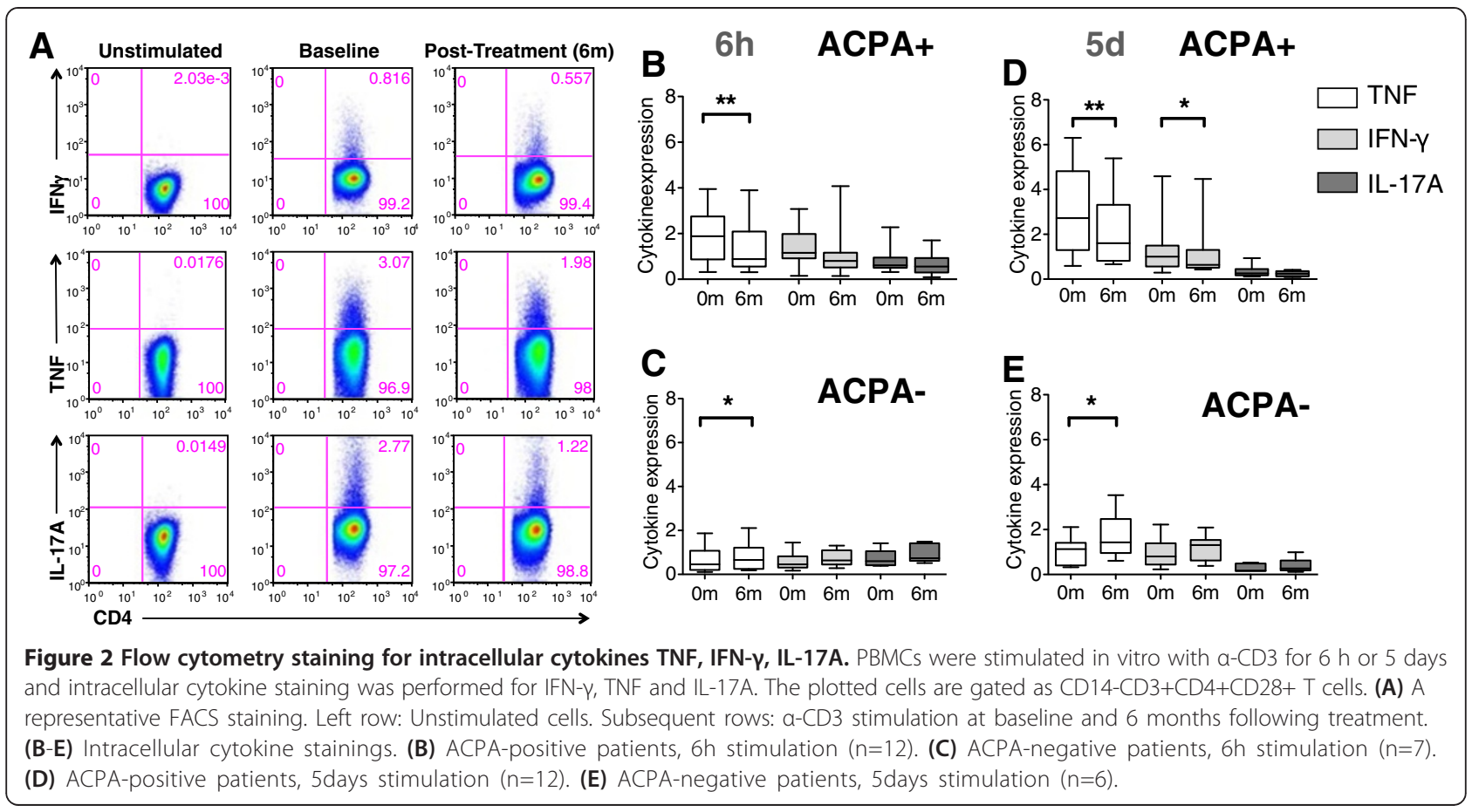

TNF/IL-17A: $\mathrm{r}=0.688, \mathrm{p}=0.002 ; \mathrm{IL}-17 \mathrm{~A} / \mathrm{IFN}-\gamma: \mathrm{r}=0.558$, $\mathrm{p}=0.016)$ was detected demonstrating that the effect of CTLA-Ig was general rather than biased.

\section{Abatacept modulates key cytokines influencing different $\mathrm{T}$ helper subsets}

Abatacept limits the immune response by binding to CD80 and 86 on antigen-presenting cells (APCs). Hence, we investigated the immune-modulatory effect of abatacept in the cell culture supernatants of polyclonal stimulated PBMCs from 17 abatacept-treated patients by luminex and a panel of 15 cytokines. We focused on cytokines relevant for the Th1, Th2 and Th17 subsets.

In ACPA-positive patients IL-3, IL-13 and IL-23 were significantly diminished after abatacept treatment (Figure 3). IL-2, -4, -7, -9, -10, -17A, -17F, -21, -22 and TNF were also diminished, but the change did not reach statistical significance. IL-1 $\beta$ levels tended to increase after abatacept treatment in this patient group.

For ACPA-negative patients IFN- $\gamma$ was significantly increased (Figure 3). Many other examined cytokines were also increased but without reaching statistical significance.

\section{Abatacept reduces regulatory $\mathrm{T}$ cell frequencies in vivo}

Next we investigated the phenotype of Tregs in patients undergoing abatacept therapy.

Polychromatic flow cytometry was performed on peripheral blood samples of $12 \mathrm{RA}$ patients taken at initiation of treatment ( 0 months) and 3 months post-treatment. In addition to FOXP3, we also investigated Helios, CD39 and CTLA4 as they have been implicated in Treg function in RA [12-16], as well as CD45RA to also address naïve Tregs.

A representative staining of FOXP3 expression before and after therapy is depicted in Figure 4A. A significant reduction in the frequency of FOXP3+ Tregs, Helios+ and CD39+ T cells was observed at 3 months as compared to baseline (Figure 4B-D). To dissect this further, we also analyzed the proportion of naïve thymusderived Tregs based on CD45RA expression in conjunction with FOXP3, the proportion of Th17-suppressive Tregs based on CD39 expression, as well as the expression of the Treg effector molecule CTLA4. As shown in Figure 4E-G, all Treg subsets were considerably reduced at the 3 month time point. For 4 of the included patients, we also studied the Treg phenotype at 6 months and the decline in frequencies remained low, suggesting that this is a general outcome of costimulationblockade and not a transient effect (Additional file 1: Figure S1).

\section{Abatacept reduces synovial T cell function in vitro}

In rheumatoid arthritis, affected joints accumulate synovial fluid that often is very cellular with substantial fractions of both effector/memory $\mathrm{T}$ cells and Tregs. To assess whether abatacept would also influence $\mathrm{T}$ cell functionality at the site of inflammation, we studied the effect of in vitro added abatacept on both synovial $\mathrm{T}$ effector and Treg function. By this approach each sample is individually controlled by the wells without abatacept. 

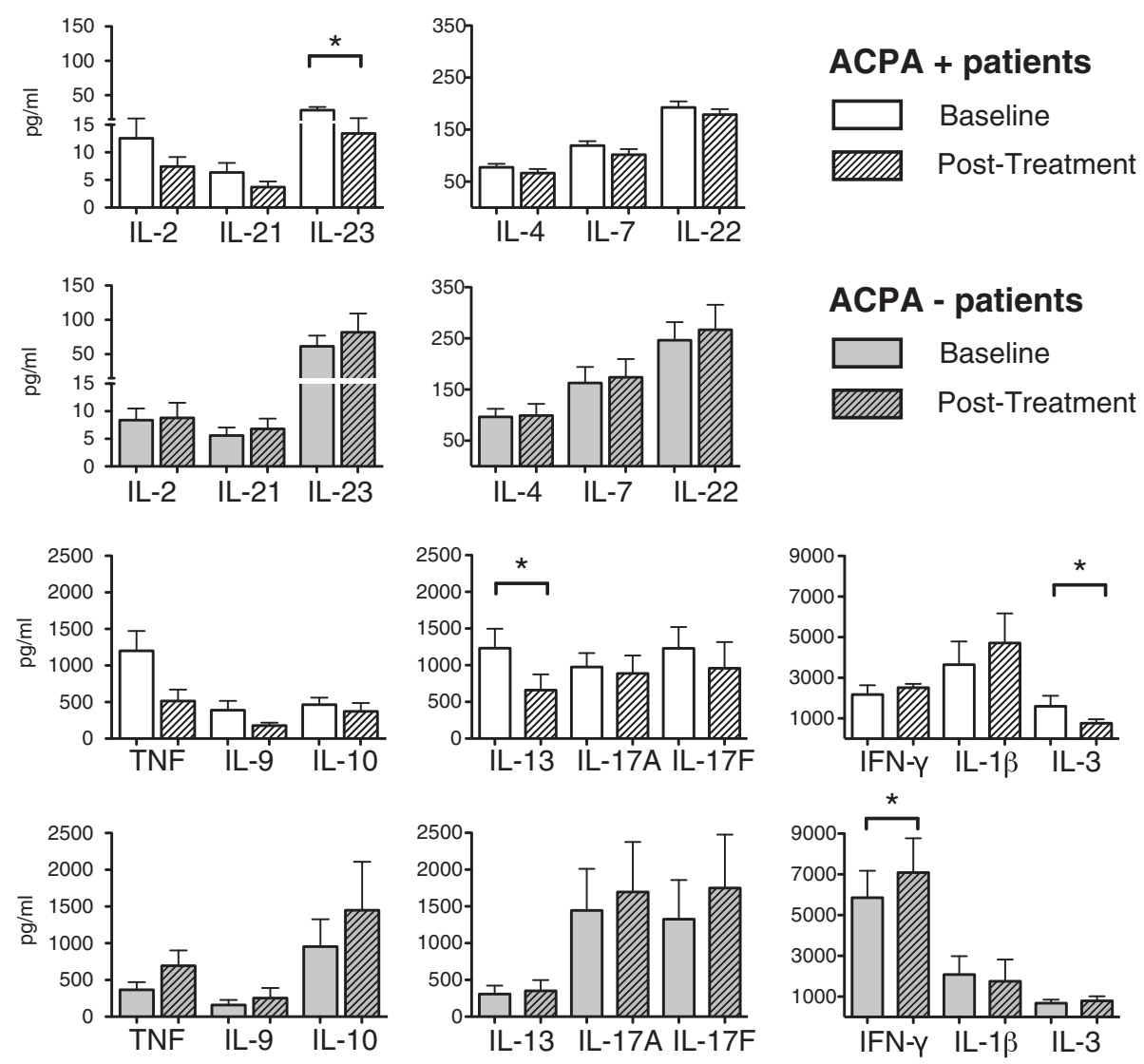

Figure 3 Cytokines in cell culture supernatants. PBMCs were stimulated in vitro with a-CD3 for 5 days and supernatants were taken and examined by the luminex method for 15 cytokines. Cytokine levels of 17 patients at baseline (non hatched bars) and post-treatment (hatched bars). White bars represent ACPA-positive patients $(n=10)$, whereas grey bars represent ACPA-negative patients $(n=7)$.

First we studied the effect of abatacept on synovial $\mathrm{T}$ cells in vitro by investigating suppression in the presence of abatacept. Treg co-culture experiments were performed but no difference in suppressive capacity was seen in cultures with abatacept compared to control cultures (Figure 5A and B). However, we observed a significant reduction of CD25-negative $\mathrm{T}$ effector cell proliferation in the presence of abatacept (Figure 5C).

Second, we studied the effects of abatacept on the whole SFMC population using polyclonal and antigen-specific stimulation. As depicted in Figure 5D, abatacept significantly down-regulated the proliferative response following polyclonal $(n=15)$ and antigen-specific $(n=7)$ stimulation. We also observed reduced IFN- $\gamma$ levels in the culture supernatants of the abatacept-treated cells (data not shown).

The reduced proliferation was confined to the autoantibody-positive fraction of the patients (Figure 5E and F).

\section{Discussion}

Abatacept is a soluble chimeric CTLA4 protein, which binds with high affinity to the B7 molecules CD80 and
CD86 expressed on antigen-presenting cells. The outcome of this blockade could be manifold, including changes of activity and lifespan of APCs and limiting the activation and re-activation of $\mathrm{CD} 4+\mathrm{T}$ cells. In the present study we demonstrate a significant downregulation of all key $\mathrm{T}$ cell effector subsets including Th1, Th2 and Th17 by abatacept. We saw these effects in the ACPA-positive patient subset, but not in the ACPA-negative patients. Further, we could show a general decrease in frequencies of regulatory $\mathrm{T}$ cells.

Today it is widely recognized that ACPA-positive and ACPA-negative RA are distinct disease sub-entities as these two phenotypes demonstrate major differences in terms of HLA-association, other genetic and environmental risk factors, clinical disease phenotype and treatment response and probably in molecular pathogenesis as well [17-21].

Clinical response to CTLA4-Ig (abatacept) can be different early in disease as compared to patients with established disease. It has also been shown that seroconversion (ACPA-positive turning into ACPA-negative) is possible in early RA patients treated with abatacept 
A

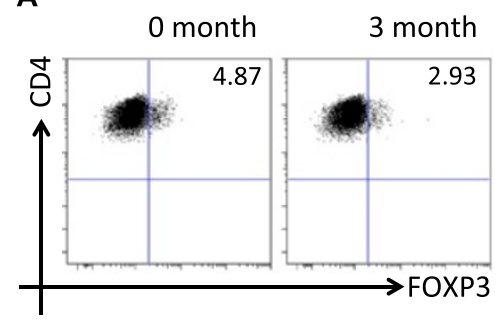

\section{B}
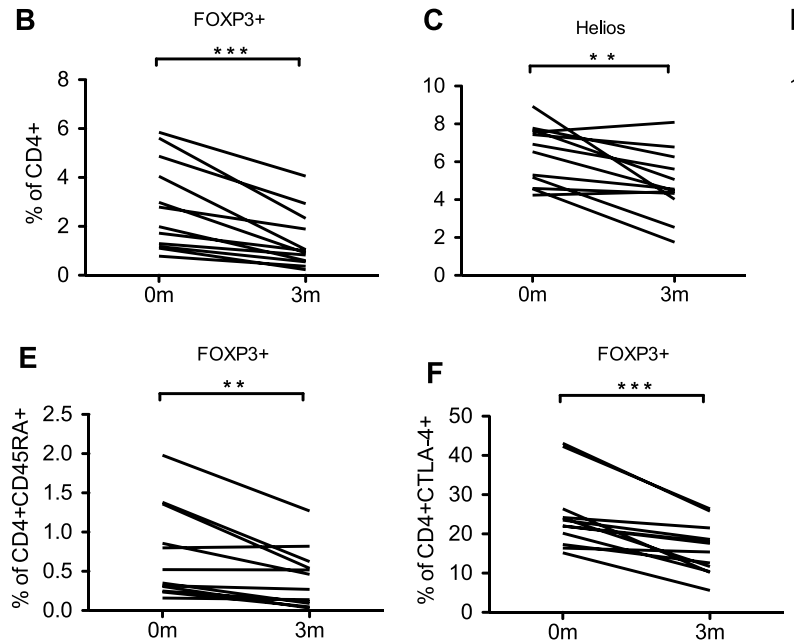
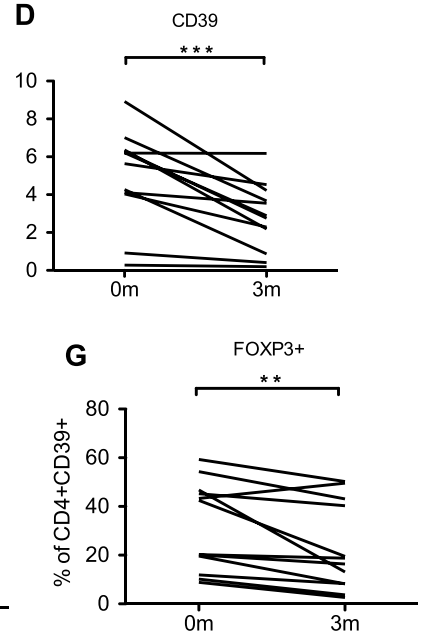

Figure 4 Treg frequency is diminished. PBMCs from baseline and 3 months following treatment $(n=12)$ were obtained and multicolor flow cytometry was performed. A general reduction in frequency of several Treg associated markers could be seen (A-G). (A) The graph depicts a representative staining of CD4+FOXP3+ Treg before and after treatment. (B) The graph displays CD4+FOXP3+ Treg, (C) Helios+ T cells, (D) CD4+CD39+ T cells, (E) CD45RA+FOXP3+ Treg, (F) CTLA4+ FOXP3+Treg, and (G) CD39+FOXP3+ Treg.

(ADJUST and AGREE trials) [22,23] suggesting that abatacept may impact on autoantibody formation. However, we could not detect any difference in ACPA levels after 6 months of treatment, but our cohort consists of patients with "long-standing" disease who have failed several biologicals prior to starting with abatacept. Interestingly it was recently published that in a cohort similar to ours (but larger), ACPA status was an independent factor positively correlating to therapy response, where ACPA-positive RA patients responded better to Abatacept treatment than ACPA-negative [11]. Still, abatacept is approved for use in both ACPA-positive and ACPA-negative patients and patients in our study who demonstrated a clinical response towards abatacept were both ACPA-positive and negative. This illustrates how therapeutic progress is possible even though the role of $\mathrm{T}$ cells in ACPA-positive vs. ACPAnegative RA is not (fully) understood.

Importantly, our study aimed at dissecting the outcome of costimulation blockade by abatacept on a cell population level. It was not powered to address clinical outcome or identify biomarkers for therapy response. In particular the number of ACPA-negative patients in our cohort was low, reflecting a typical RA cohort of patients with long-standing disease.
To address the question of which cells are affected by abatacept therapy, we studied both peripheral blood samples of patients undergoing therapy as well as synovial fluid cells from disease-active joints where abatacept has been added to the cultures. Recently another study focusing on $\mathrm{T}$ helper cells in affected joints was published. Consistent with our data, they showed that CTLA4-Ig leads to reduced levels of proinflammatory cytokines IFN- $\gamma$ and IL-2 but they also reported increased levels of IL-10 and TGF- $\beta$. ACPA status was not reported [24].

In our study we investigated cytokine production representative for different $\mathrm{T}$ cell subsets (Th1, Th2, Th17), utilizing PBMCs of abatacept-treated patients by two different methodological approaches. Strikingly, a reduction in Th1, Th2 and Th17 cytokines in ACPA-positive patients was seen, but not in ACPA-negative patients. The observed down-regulation of IFN- $\gamma$ is supported by a previous study by Cutolo et al. showing that abatacept in vitro can decrease synovial macrophage activation when co-cultured with $\mathrm{T}$ cells accompanied with a decreased production of proinflammatory cytokines such as IL-6 and TNF [25]. A few years ago, Buch et al. investigated synovial biopsies from established RA and could demonstrate a decrease of number of B cells after 16 


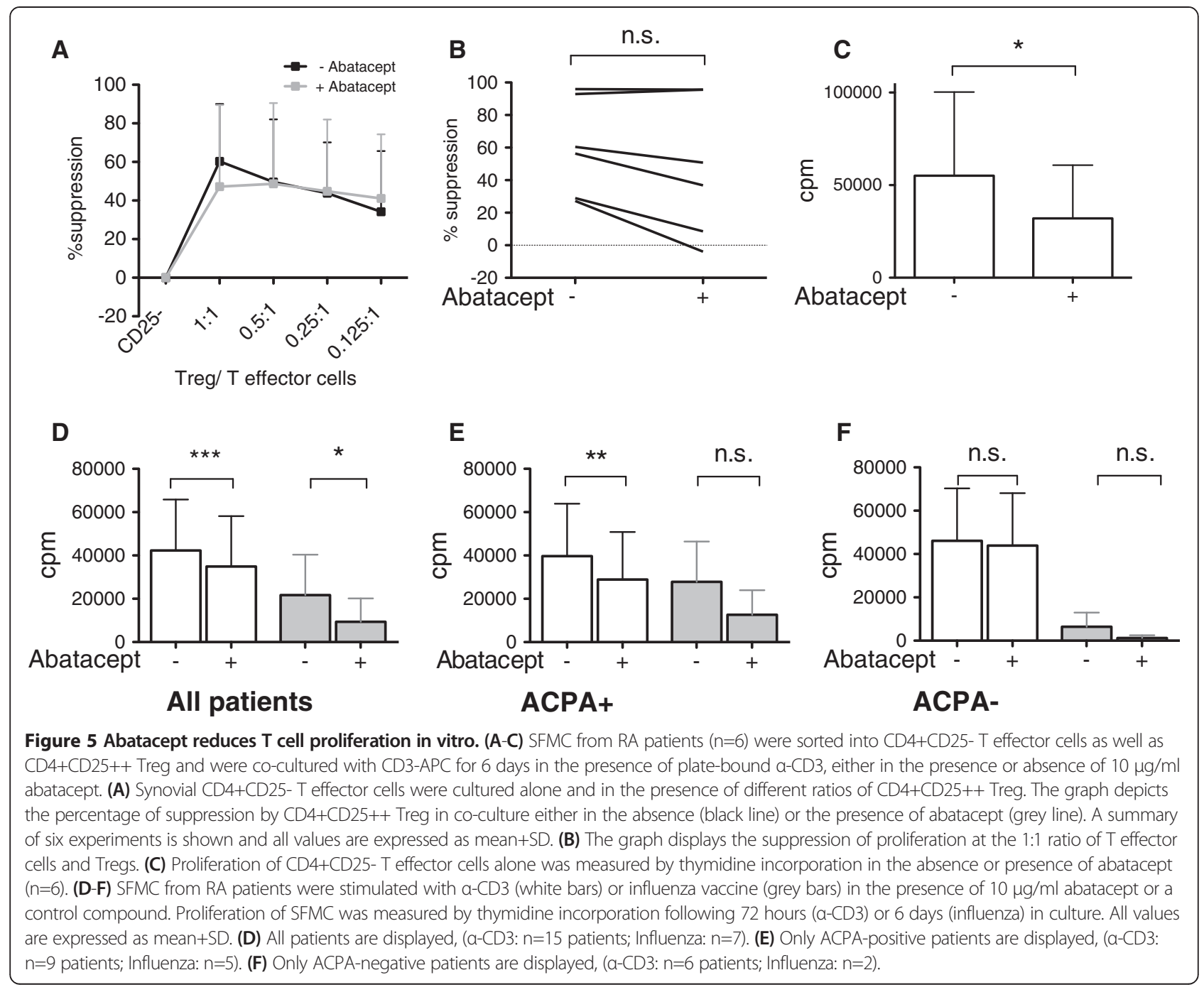

weeks of therapy and reduced mRNA levels for IFN- $\gamma$ [26]. The ACPA status was not reported in these studies.

We also explored the regulatory $\mathrm{T}$ cell compartment (Treg) since it is well established that optimal Treg functionality is dependent on costimulation as antigen-specific Tregs are the most efficient suppressor cells [27]. We have recently shown that synovial Tregs proliferate in vivo [28], suggesting that Tregs in the rheumatic joint interact with their cognate antigens. In the same study, we also showed that biological therapies targeting TNF and IL-6R could lead to increased suppression by synovial Tregs [28]. This is in line with studies performed on Tregs in the circulation of RA patients $[29,30]$. However, we could not detect increased suppressive capacity, even though the T effector proliferation rate was reduced by abatacept. This observation supports the importance of costimulation for Treg function. Thus, the clinical efficacy seen with abatacept is not due to increased Treg functionality.
The focus of the phenotype study was on natural Tregs expressing the lineage marker FOXP3, and subsets thereof. Overall we found a general reduction of FOXP3+ natural Tregs in the periphery, supporting the data by AlvarezQuiroga et al, who demonstrated reduced Treg frequencies based on FOXP3 and CD25 expression [31].

\section{Conclusion}

Our study shows that abatacept has a significant impact on T effector functions of the Th1, Th2 and Th17 subsets and that effects were predominantly seen in the ACPA-positive patient subset. Treg frequencies were diminished in the periphery, however no significant changes in function were seen in synovial in vitro co-culture essays. This data gives further evidence that RA has to be seen as a disease with several different sub-entities, and supports the view that ACPA-positive and ACPA-negative patients 
represent immunologically distinct disease phenotypes, with repercussions for treatment strategies.

\section{Methods}

\section{Patients and samples}

Two cohorts of patients were collected: a first cohort consisted of a total of 29 patients treated with abatacept. Patients had a mean age of 55(18-74), 79\% female $(\mathrm{n}=23), 65 \%$ ACPA-positive $(\mathrm{n}=19)$. PBMCs and serum from RA patients were collected at month 0 , on initiation of abatacept therapy, and after 3 months and 6 months of therapy. Patients were treated with abatacept by intravenous infusion according to baseline weight $(<60 \mathrm{~kg}$, $500 \mathrm{mg}$; $60-100 \mathrm{~kg}, 750 \mathrm{mg}$; and > $100 \mathrm{~kg}, 1000 \mathrm{mg}$ ) on days $1,15,29$, and then every 4 weeks. Clinical assessment of the patients was performed after 3 and 6 months and the clinical response was evaluated using the European League Against Rheumatism (EULAR) response criteria, based on the disease activity score using the 28 joint count (DAS28) and erythrocyte sedimentation rate. The second cohort consisted of 16 RA and 6 JIA patients, from which Synovial fluid and serum was obtained. (Mean age 51(23-86), 77\% female ( $\mathrm{n}=17), 50 \%$ ACPApositive $(\mathrm{n}=11))$. All patients attended the Rheumatology Clinic at Karolinska University Hospital. All RA patients fulfilled the ACR criteria for RA [32].

Peripheral blood and synovial fluid samples prepared by ficoll (Ficoll-Paque Plus, GE Healthcare, Uppsala, Sweden) separation and cryopreserved until use. Serum samples were stored at $-70^{\circ} \mathrm{C}$ until use.

The ethics review board of the Karolinska University Hospital approved this study, and all study subjects gave informed consent according to the declaration of Helsinki.

\section{Anti-CCP assay (ACPA)}

Serum samples from 33 patients were used to determine anti-citrullinated cyclic peptides (anti-CCP) levels using the anti-CCP-2 ELISA kit (Immunoscan RA Mark 2; EuroDiagnostica, Arnhem, The Netherlands) according to the manufacturer's instructions.

\section{Intracellular cytokine staining}

Cells from 19 patients collected at 0 and 6 months after abatacept treatment were cultured for 6 h or 5 days in complete media (RPMI, HEPES, L-Glutamine, Penicillin, Streptomycin) containing 5\% human serum and stimulated with plate-bound $\alpha$-CD3 monoclonal antibody $(2.5 \mu \mathrm{g} / \mathrm{ml}$, clone OKT-3). All cultures were incubated at $37^{\circ} \mathrm{C}, 5 \%$ $\mathrm{CO}_{2}$. Supernatants were collected on day 5 and stored at $-80^{\circ} \mathrm{C}$ until use.

In order to prevent produced cytokines from being secreted, $10 \mu \mathrm{g} / \mathrm{ml}$ Brefeldin A (Sigma-Aldrich, Steinheim, Germany) was added to the cultures $4 \mathrm{~h}$ prior to harvesting. Extracellular and intracellular cytokine staining was performed using Cytofix/Cytoperm Kit (BD) according to the manufacturer's instructions. Antibodies: $\alpha-C D 28$ PE (clone: L293, BD), $\alpha-C D 14$ APC Cy7 (clone: MphiP9, BD), $\alpha-C D 4$ PeCy7 (clone: SK3, BD), $\alpha-C D 3$ PB (clone: UCHT1, BD and Biolegend), $\alpha-\mathrm{IFN}-\gamma$ FITC (clone: B27, BD), $\alpha$-TNF PerCP Cy5.5 (clone: Mab11, Biolegend), $\alpha$-IL17 Alexa 647 (clone: BL168, Biolegend).

Beriglobin was added in order to prevent unspecific staining and LIVE/DEAD Aqua Dead Cell Stain (Invitrogen) was used to exclude dead cells. The PBMCs were run on a Beckman Coulter CyAn. Analyses were performed with FlowJo software, version 8.1.0 or higher (Treestar Inc.).

\section{Luminex analysis of cell culture supernatants}

Cytokine analysis was performed on the collected supernatant samples from the 5 day cultures using the multiplex assay LEGENDplex (Biolegend, San Diego, CA, USA) and read on a Luminex $100^{\text {in }}$ platform (Bio-Rad, Hercules, CA, USA) with Bio-Rad software. The cytokines analyzed were; interleukin IL-1 $\beta$ (1.9), IL-2 (0.3), IL-3 (4.1), IL-4 (0.6), IL-7 (1.5), IL-9 (0.1), IL-10 (0.2), IL-13 (0.2), IL-17A (0.7), IL-17F (1.6), IL-21 (0.2), IL-22 (4.4), IL-23 (1.2), TNF (0.6) and IFN- $\gamma(0.2)$. Detection limits for these cytokines/chemokines are indicated in brackets in $\mathrm{pg} / \mathrm{ml}$.

\section{Phenotypic characterization of Tregs}

PBMCs taken from 12 patients at 0 and 3 months posttreatment were utilized for phenotypic analyses by flow cytometry. Intranuclear staining of FOXP3 and Helios was performed using FOXP3/Transcription factor staining kit (eBioscience, San Diego, CA, USA) according to the manufacturer's instructions. Antibodies: $\alpha$-CD3 Alexa700 (clone: UCHT1, Biolegend), $\alpha$-CD3 FITC (clone: UCHT1, $\mathrm{BD}), \alpha-\mathrm{CD} 4$ PE (clone: RPA-T4, BD), $\alpha-\mathrm{CD} 39$ FITC (clone: A1, Biolegend), $\alpha$-CD45RA ECD (clone: 2H4LDH11LDB9, Beckman Coulter), $\alpha$-Helios Alexa647 (clone: 22F6, Biolegend), $\alpha$-FOXP3 PB (clone: 206D, Biolegend), $\alpha$-CTLA4 PE (clone: BNI-3, BD). LIVE/DEAD Near-IR Dead Cell Stain (Invitrogen) was used to exclude dead cells. The PBMCs were run on a Beckman Coulter Gallios (Beckman Coulter, Brea, CA, USA). Analyses were performed with FlowJo software, version 8.1.0 or higher (Treestar Inc., Ashland, OR; USA).

\section{In vitro study of SFMC in the presence of abatacept}

SFMC $(n=16)$ were thawed and stimulated with either plate-bound $\alpha$-CD3 $(1 \mu \mathrm{g} / \mathrm{ml}$, clone: OKT-3) for 72 hours or with influenza vaccine (Fluvirin vaccine 2001/2002, Evans Vaccines Limited, Liverpool, UK) for 6 days. For Treg suppression assays, SFMC $(n=6)$ were thawed and sorted by flow cytometry into CD3-APC, CD3+4+25- effector $\mathrm{T}$ cells and CD3+4+25++ Tregs and co-cultured 
with plate-bound $\alpha$-CD3 $(0.5 \mu \mathrm{g} / \mathrm{ml}$, clone OKT-3) for 6 days [28] in presence or absence of $10 \mu \mathrm{g} / \mathrm{ml}$ abatacept. For total SFMC Abatacept or a control compound (Chimeric L6 Bd2.1 IgG) was added at $10 \mu \mathrm{g} / \mathrm{ml}$ (both provided by Bristol-Myers Squibb, Princeton, NJ, USA), which represents the physiological concentration in the blood of patients post-treatment [33]. During the last 15-18 hours of the incubation ${ }^{3} \mathrm{H}$-labelled thymidine $(1 \mathrm{uCi} /$ well, Perkin Elmer, Boston, MA, USA) was added to the wells and the counts per minute were measured, indicating cell division. Cytokines were measured in supernatants with the CBA Inflammation Kit (Becton Dickinson (BD), San Jose, CA, USA) according to the manufacturer's instructions and were acquired and analyzed with a FACS calibur (BD).

\section{Statistical analysis}

A nonparametric Wilcoxon signed-rank test was used to compare control and abatacept-treated SFMC cultures, Treg co-cultures, Treg frequencies, and differences between baseline and post-treatment cytokine secretion and cytokine levels. $P$ values less than 0.05 were considered statistically significant. Spearman's rank correlation coefficient was used to analyze the ratio between different combinations of cytokines.

All statistical analyses were performed using Prism 5.0 (GraphPad Software, La Jolla, CA, USA).

\section{Additional file}

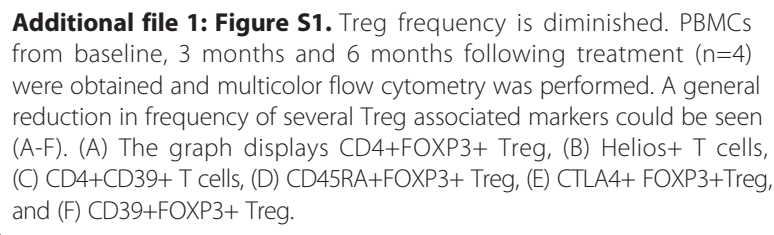
were obtained and multicolor flow cytometry was performed. A general reduction in frequency of several Treg associated markers could be seen (A-F). (A) The graph displays CD4+FOXP3+ Treg, (B) Helios+ T cells, (C) CD4+CD39+ T cells, (D) CD45RA+FOXP3+ Treg, (E) CTLA4+ FOXP3+Treg, and (F) CD39+FOXP3+ Treg.

\section{Competing interests}

Our Rheumatology unit receives support from a national Swedish initiative for research, patient participation and collaboration with industry concerning inflammatory diseases. This consortium receives financial contributions for infrastructure as well as for distinct research projects from several companies including NovoNordisk, Pfizer, Sobi and BMS. The rheumatology unit also receives support from the Innovative Medicines Initiative BTCure. Also in this consortium, several companies including Astra-Zeneca, NovoNordisk, UCB and BMS participate. Our head of research, professor Lars Klareskog is PI and financially responsible for both these consortia. Consulting fees/honoraria for RVV (<10,000\$): Abbott, Bristol-Myers Squibb, Merck, Pfizer, GSK, Roche, UCB Pharma. Grant/research support for RvV: same as above.

\section{Authors' contributions}

JP carried out and analyzed the proliferation study, flow cytometric study and luminex, participated in its design and drafted the manuscript. JH carried out phenotypic and functional assessment of Treg studies and participated in drafting the manuscript. SR and KM participated in the proliferation study and the design. Rv $V$ was responsible for patients' inclusion and interpretation of clinical data. VM conceived the study, and participated in its design and coordination and helped to draft the manuscript. All authors read and approved the final manuscript.

\section{Acknowledgements}

The authors thank the staff and patients at the Rheumatology Clinic of Karolinska University Hospital, especially Eleanor Gullström, Eva Jemseby, Gull-Britt Almgren and Julia Boström for organizing the sampling, storage, and administration of biomaterial, and Annika van Vollenhoven for excellent cell sorting. We would also like to thank Johanna Steen and Fiona Murray for critical reading of the manuscript and linguistic advice. This study is supported by grants from the Margaretha af Ugglas Foundation, the Swedish Association against Rheumatism, the Swedish Medical Association, the King Gustaf V 80 year Foundation, the Swedish Research Council, the EU FP7 project Masterswitch (HEALTH-F2-2008223404) and the IMI JU funded project BTCure 115142-2.

\section{Author details}

${ }^{1}$ Rheumatology Unit, Department of Medicine at Karolinska University Hospital, Karolinska Institute, Solna, Stockholm, Sweden. ${ }^{2}$ Unit for Clinical Therapy Research, Inflammatory Diseases, Karolinska Institute, Solna, Stockholm, Sweden.

Received: 15 April 2013 Accepted: 31 July 2013

Published: 5 August 2013

\section{References}

1. Nepom GT: Major histocompatibility complex-directed susceptibility to rheumatoid arthritis. Adv Immunol 1998, 68:315-332.

2. De Rycke L, Peene I, Hoffman IE, Kruithof E, Union A, Meheus L, Lebeer K, Wyns B, Vincent C, Mielants $H$, et al: Rheumatoid factor and anticitrullinated protein antibodies in rheumatoid arthritis: diagnostic value, associations with radiological progression rate, and extra-articular manifestations. Ann Rheum Dis 2004, 63(12):1587-1593.

3. Niewold TB, Harrison MJ, Paget SA: Anti-CCP antibody testing as a diagnostic and prognostic tool in rheumatoid arthritis. Qjm 2007, 100(4):193-201.

4. Dolhain RJ, van der Heiden AN, ter Haar NT, Breedveld FC, Miltenburg AM: Shift toward T lymphocytes with a T helper 1 cytokine-secretion profile in the joints of patients with rheumatoid arthritis. Arthritis Rheum 1996, 39(12):1961-1969.

5. Hwang SY, Kim HY: Expression of IL-17 homologs and their receptors in the synovial cells of rheumatoid arthritis patients. Mol Cells 2005, 19(2):180-184

6. Chabaud M, Durand JM, Buchs N, Fossiez F, Page G, Frappart L, Miossec P. Human interleukin-17: A T cell-derived proinflammatory cytokine produced by the rheumatoid synovium. Arthritis Rheum 1999, 42(5):963-970.

7. Esensten JH, Wofsy D, Bluestone JA: Regulatory T cells as therapeutic targets in rheumatoid arthritis. Nat Rev Rheumatol 2009, 5(10):560-565.

8. Cao D, Malmstrom V, Baecher-Allan C, Hafler D, Klareskog L, Trollmo C: Isolation and functional characterization of regulatory CD25brightCD4+ $T$ cells from the target organ of patients with rheumatoid arthritis. Eur $J$ Immunol 2003, 33(1):215-223.

9. van Amelsfort JM, Jacobs KM, Bijlsma JW, Lafeber FP, Taams LS: CD4(+) $\mathrm{CD} 25(+)$ regulatory $T$ cells in rheumatoid arthritis: differences in the presence, phenotype, and function between peripheral blood and synovial fluid. Arthritis Rheum 2004, 50(9):2775-2785.

10. Maxwell L, Singh JA: Abatacept for rheumatoid arthritis. Cochrane Database Syst Rev 2009, 4, CD007277.

11. Gottenberg JE, Ravaud P, Cantagrel A, Combe B, Flipo RM, Schaeverbeke T, Houvenagel E, Gaudin P, Loeuille D, Rist S: Positivity for anti-cyclic citrullinated peptide is associated with a better response to abatacept: data from the 'Orencia and Rheumatoid Arthritis' registry. Ann Rheum Dis 2012, 71(11):1815-1819.

12. Getnet D, Grosso JF, Goldberg MV, Harris TJ, Yen HR, Bruno TC, Durham NM, Hipkiss EL, Pyle KJ, Wada S, et al: A role for the transcription factor Helios in human CD4(+)CD25(+) regulatory T cells. Mol Immunol 2010, 47(7-8):1595-1600.

13. Thornton AM, Korty PE, Tran DQ, Wohlfert EA, Murray PE, Belkaid Y, Shevach EM: Expression of Helios, an Ikaros transcription factor family member, differentiates thymic-derived from peripherally induced Foxp3+ T regulatory cells. J Immunol 2010, 184(7):3433-3441.

14. Moncrieffe $H$, Nistala K, Kamhieh Y, Evans J, Eddaoudi A, Eaton S, Wedderburn LR: High expression of the ectonucleotidase CD39 on T cells from the inflamed site identifies two distinct populations, one regulatory and one memory T cell population. J Immunol 2010, 185(1):134-143. 
15. Fletcher JM, Lonergan $\mathrm{R}$, Costelloe $\mathrm{L}$, Kinsella K, Moran B, O'Farrelly $\mathrm{C}$, Tubridy N, Mills KH: CD39+Foxp3+ regulatory T Cells suppress pathogenic Th17 cells and are impaired in multiple sclerosis. J Immunol 2009, 183(11):7602-7610.

16. Wing K, Ekmark A, Karlsson H, Rudin A, Suri-Payer E: Characterization of human CD25+ CD4+ T cells in thymus, cord and adult blood. Immunology 2002, 106(2):190-199.

17. Chatzidionysiou K, Lie E, Nasonov E, Lukina G, Hetland ML, Tarp U, Gabay C, van Riel PL, Nordstrom DC, Gomez-Reino J, et al: Highest clinical effectiveness of rituximab in autoantibody-positive patients with rheumatoid arthritis and in those for whom no more than one previous TNF antagonist has failed: pooled data from 10 European registries. Ann Rheum Dis 2011, 70(9):1575-1580.

18. Ding B, Padyukov L, Lundstrom E, Seielstad M, Plenge RM, Oksenberg JR, Gregersen PK, Alfredsson L, Klareskog L: Different patterns of associations with anti-citrullinated protein antibody-positive and anti-citrullinated protein antibody-negative rheumatoid arthritis in the extended major histocompatibility complex region. Arthritis Rheum 2009, 60(1):30-38.

19. Klareskog L, Catrina Al, Paget S: Rheumatoid arthritis. Lancet 2009, 373(9664):659-672.

20. van Dongen $H$, van Aken J, Lard LR, Visser K, Ronday HK, Hulsmans HM, Speyer I, Westedt ML, Peeters AJ, Allaart CF, et al: Efficacy of methotrexate treatment in patients with probable rheumatoid arthritis: a double-blind, randomized, placebo-controlled trial. Arthritis Rheum 2007,

56(5):1424-1432

21. Isaacs JD, Cohen SB, Emery P, Tak PP, Wang J, Lei G, Williams S, Lal P, Read SJ: Effect of baseline rheumatoid factor and anticitrullinated peptide antibody serotype on rituximab clinical response: a meta-analysis. Ann Rheum Dis 2013, 72(3):329-336.

22. Emery $P$, Durez $P$, Dougados $M$, Legerton CW, Becker JC, Vratsanos $G$, Genant HK, Peterfy C, Mitra P, Overfield S, et al: Impact of T-cell costimulation modulation in patients with undifferentiated inflammatory arthritis or very early rheumatoid arthritis: a clinical and imaging study of abatacept (the ADJUST trial). Ann Rheum Dis 2010, 69(3):510-516.

23. Westhovens $R$, Robles $M$, Ximenes $A C$, Nayiager $S$, Wollenhaupt J, Durez $P$, Gomez-Reino J, Grassi W, Haraoui B, Shergy W, et al: Clinical efficacy and safety of abatacept in methotrexate-naive patients with early rheumatoid arthritis and poor prognostic factors. Ann Rheum Dis 2009, 68(12):1870-1877.

24. Kormendy D, Hoff H, Hoff P, Broker BM, Burmester GR, Brunner-Weinzierl MC: Impact of the CTLA-4/CD28 axis on the processes of joint inflammation in rheumatoid arthritis. Arthritis Rheum 2013, 65(1):81-87.

25. Cutolo M, Soldano S, Montagna P, Sulli A, Seriolo B, Villaggio B, Triolo P, Clerico P, Felli L, Brizzolara R: CTLA4-Ig interacts with cultured synovial macrophages from rheumatoid arthritis patients and downregulates cytokine production. Arthritis Res Ther 2009, 11(6):R176.

26. Buch MH, Boyle DL, Rosengren S, Saleem B, Reece RJ, Rhodes LA, Radjenovic A, English A, Tang H, Vratsanos G, et al: Mode of action of abatacept in rheumatoid arthritis patients having failed tumour necrosis factor blockade: a histological, gene expression and dynamic magnetic resonance imaging pilot study. Ann Rheum Dis 2009, 68(7):1220-1227.

27. Masteller EL, Tang Q, Bluestone JA: Antigen-specific regulatory T cells-ex vivo expansion and therapeutic potential. Semin Immunol 2006, 18(2):103-110.

28. Herrath J, Muller M, Amoudruz P, Janson P, Michaelsson J, Larsson PT Trollmo C, Raghavan S, Malmstrom V: The inflammatory milieu in the rheumatic joint reduces regulatory T-cell function. Eur J Immunol 2011 41(8):2279-2290.

29. Ehrenstein MR, Evans JG, Singh A, Moore S, Warnes G, Isenberg DA Mauri C: Compromised function of regulatory $T$ cells in rheumatoid arthritis and reversal by anti-TNFalpha therapy. The J Exp Med 2004, 200(3):277-285

30. Valencia X, Stephens G, Goldbach-Mansky R, Wilson M, Shevach EM, Lipsky PE: TNF downmodulates the function of human CD4+CD25hi T-regulatory cells. Blood 2006, 108(1):253-261.

31. Alvarez-Quiroga C, Abud-Mendoza C, Doniz-Padilla L, Juarez-Reyes A, Monsivais-Urenda A, Baranda L, Gonzalez-Amaro R: CTLA-4-Ig therapy diminishes the frequency but enhances the function of Treg cells in patients with rheumatoid arthritis. J Clin Immunol 2011, 31(4):588-595.
32. Arnett FC, Edworthy SM, Bloch DA, McShane DJ, Fries JF, Cooper NS, Healey LA, Kaplan SR, Liang MH, Luthra HS, et al: The American Rheumatism Association 1987 revised criteria for the classification of rheumatoid arthritis. Arthritis Rheum 1988, 31(3):315-324.

33. Nadler S, Townsend R, Mikesell G, Rouleau K, Davis P, Calore J, Summerill R, Tay L: Abatacept (CTLA4lg; BMS-188667) significantly inhibits T-CELL proliferation in vitro at clinically relevant concentrations. Ann Rheum Dis 2004, 63:142-143.

doi:10.1186/1471-2172-14-34

Cite this article as: Pieper et al:: CTLA4-lg (abatacept) therapy modulates $T$ cell effector functions in autoantibody-positive rheumatoid arthritis patients. BMC Immunology 2013 14:34.

\section{Submit your next manuscript to BioMed Central and take full advantage of:}

- Convenient online submission

- Thorough peer review

- No space constraints or color figure charges

- Immediate publication on acceptance

- Inclusion in PubMed, CAS, Scopus and Google Scholar

- Research which is freely available for redistribution 